\title{
Clinical commentary: Systemic and subclinical adverse effects of re- peated botulinum toxin a injections to decrease spasticity in adults affected by stroke undergoing rehabilitation
}

Maria Amelia Chang*

Neuro-IFRAH Organization, San Diego, CA

\section{Article Info}

\section{Article Notes}

Received: June 30, 2016

Accepted: September 20, 2016

\section{${ }^{*}$ Correspondence:}

Dr. Maria Amelia Chang, Neuro-IFRAH Organization, San Diego, $\mathrm{CA}$

Telephone: 310713 2958; Email: Info@Neuro-IFRAH.org

(c) 2016 Chang MA. This article is distributed under the terms of the Creative Commons Attribution 4.0 International License

\section{Keywords:}

Adverse effects

Botox

Post-stroke spasticity

\section{ABSTRACT}

This is a clinical commentary that expands on an initial attempt to classify possible adverse effects ( $A E$ ) of repeated and long-term use of Botox A (BTX) to manage post-stroke spasticity into three types, local, systemic and subclinical $A E$. Clinical manifestations of non-local, systemic AE from widespread diffusion of BTX are presented to help clinicians and researchers recognize changes that may develop in post-stroke patients. Subclinical AE of muscle atrophy and bone degradation may hinder return of motor control and increase certain risk factors. Even with increased trend in the use of BTX, very little is written about long term effects of repeated BTX injections for post-stroke spasticity coupled by fewer clinicians who report what they find in actual practice. Although published studies infrequently report $A E$, it will be an error if it is attributed to an extension of the disease process in stroke.

Botulinum toxin A (BTX) is well-studied as a highly safe, welltolerated and effective pharmacologic agent for many movement disorders including post-stroke spasticity ${ }^{1-3}$. BTX injections to manage post-stroke spasticity in the upper and lower extremity has increased over the last few decades for long-term management of the motor disorder. With the increasing trend toward repeated injections and higher dosages, there are some studies that describe adverse effects (AE) with repeated use. Varghese-Kroll and Elovic (2009) reported the first case of BTX diffusion to the contralateral side after higher dose injections ${ }^{4}$. A multi-center randomized control trial, Botulinum Toxin for the Upper Limb after Stroke (BoTULS) administered BTX in a three, six and nine month period to over three hundred participants in the initial phase ${ }^{5}$. This study reported adverse events in different phases of the study including one described as serious $\mathrm{AE}$, "dysphagia believed potentially related to botulinum toxin" ${ }^{\text {. }}$. Chang (2015) briefly summarized some studies in a Table 1 that specifically report these AE: ${ }^{6}$

Furthermore, investigative studies on animals have shown BTX changes the mechanical properties of muscles, and affect normal muscle and bone homeostasis ${ }^{11-12}$. Thus based on published data, possible adverse effects (AE) from repeated Botox A (BTX) injections to decrease post-stroke spasticity can be classified into three types: Local AE, Systemic AE and Subclinical $\mathrm{AE}^{6}$. This initial attempt to classify possible AE from long-term use of BTX helps inform clinicians and researchers in the field of stroke rehabilitation how these AEs may affect a patient's ability to participate in their rehabilitation program. Recognizing the types of $\mathrm{AE}$ from frequent, and long-term chemodenervation of BTX, a muscle paralytic drug 


\begin{tabular}{|c|c|c|c|}
\hline Author, Study Design & Aim of Study & Measurement Method & Reported \% of adverse events \\
\hline $\begin{array}{l}\text { Muller et al (2012), } \\
\text { Prospective observational } \\
\text { study }\end{array}$ & $\begin{array}{l}\text { To determine the safety and } \\
\text { efficacy of botox for spasticity in } \\
\text { clinical practice. }\end{array}$ & Four-point self-reprt scale & $7.2 \%$ of 406 patients \\
\hline $\begin{array}{l}\text { Crowner et al (2010), } \\
\text { Case series } 3 \text { patients and } \\
\text { literature review }\end{array}$ & $\begin{array}{l}\text { To describe and discuss systemic } \\
\text { adverse effects after repeated } \\
\text { botox injections. }\end{array}$ & $\begin{array}{l}\text { Various methods: } \\
\text { EMG/ nerve conduction study. } \\
\text { Self report. } \\
\text { Neurological exam. }\end{array}$ & $100 \%$ of 3 patients \\
\hline $\begin{array}{l}\text { Roche et al (2008), } \\
\text { Retrospective cohort study }\end{array}$ & $\begin{array}{l}\text { To study the incidence of clinical } \\
\text { signs due to botox diffusion }\end{array}$ & $\begin{array}{l}\text { Clinical and neurological exam } \\
\text { Single fiber EMG }\end{array}$ & $2.6 \%$ (5 of 187 patients) \\
\hline $\begin{array}{l}\text { Gordon et al (2004), }{ }^{9} \\
\text { Double-blind controlled trial }\end{array}$ & $\begin{array}{l}\text { To evaluate the long-term } \\
\text { efficacy and safety of botox for } \\
\text { spasticity in wrist and finger } \\
\text { muscles }\end{array}$ & $\begin{array}{l}\text { Various methods: } \\
\text { Disability scale } \\
\text { Ashworth scale } \\
\text { Test for antibodies } \\
\text { Self-report }\end{array}$ & $\begin{array}{l}56.4 \% \text { in period } 1 \text { ( } 62 \text { of } 122 \\
\text { patients) } \\
18.2 \% \text { in period } 2 \text { ( } 20 \text { of } 110 \text { patients) }\end{array}$ \\
\hline $\begin{array}{l}\text { Sheean et al }(2010),{ }^{10} \\
\text { Literature review }\end{array}$ & $\begin{array}{l}\text { To provide best practice } \\
\text { guidance in the use of botox for } \\
\text { upper limb spasticity }\end{array}$ & $\begin{array}{l}\text { Various individualized, standardized } \\
\text { and global scales }\end{array}$ & $\begin{array}{l}\text { Varied AEs from different studies } \\
\text { (from 1998-2009) reported range: } \\
\text { none, mild, major, local and systemic. }\end{array}$ \\
\hline
\end{tabular}

Table 1: Chang (2015)

Chang MA. Possible Adverse Effects of Repeated Botulinum Toxin A Injections to Decrease Post- Stroke Spasticity in Adults Undergoing Rehabilitation. Journal of Allied Health. 2015; 44: 3

will help clinicians identify its manifestations in patients and perhaps develop a uniform tool to report these observed events.

Briefly, local AE are commonly reported like pain and hematoma from the injection process. It is often short duration and contained within the targeted muscles or injected sites ${ }^{7}$. This clinical commentary expands on nonlocal AE: Systemic AE and Subclinical AE that is described as rare occurrence and identified mainly through selfreport and non- uniform tools to monitor the varied types of $\mathrm{AE}$.

As reported by Crowner (2010), generalized weakness or transient fatigue can lead to increased falls, gait instability, difficulty in climbing stairs or getting up from a chair ${ }^{2}$. General malaise, flu-like symptoms, speech difficulties from dysphonia and dysarthria can occur. In patients that receive repeated BTX injections and physical rehabilitation to manage post-stroke spasticity, systemic widespread diffusion of BTX can manifest as sudden change in participation levels. The vascular diffusion of BTX to non-injected groups may exaggerate the decrease in motor control because the activity of adjacent or distant muscles are also depressed. In addition, temporary weakening of the non-injected muscles may involve the contralateral limb that affects a patient's walking performance and increase the risk for falls due to incoordination. A patient may report of unexplained increased functional limitations and thus, need increased level of assistance from caregivers or therapists.

Attempts to find factors that predispose patients to develop systemic AE may be difficult because it occurs variably. It is not clear if repeated injections increase the severity of $\mathrm{AEs}^{1-3}$. Published studies report that systemic AE are rare and are more likely to happen when the total dose per visit is relatively large ${ }^{1-4}$. Electromyography (EMG) and neuromuscular biopsy have been used to confirm muscle denervation and link clinical signs from BTX diffusion distant from the injection site $\mathrm{e}^{8,11,12}$.

Subclinical AE that manifest as abnormal changes in muscle and bone tissues have been identified in animal studies through EMG and muscle biopsies. Repeated acute muscle paralysis from BTX disturbs the normal muscle bone homeostasis due to blockage of release or transport of certain biochemical factors; a process that leads to bone resorption and osteopenia ${ }^{12-13}$. Raphael et al (2014) reported that the paralytic action of BTX in rabbit's jaw muscles caused osteoporosis and negatively affected the overall jaw bone health ${ }^{14}$. Although human studies are needed for establishing clinical significance of these animal studies, concerns have been raised that bone loss associated with paralysis from BTX may increase the rate of bone degradation and predispose osteoporosis. For example, a patient with onset of systemic $\mathrm{AE}$, like generalized weakness and sudden change in motor abilities, increases his risk of fall and fracture from poor bone health.

Subclinical changes in muscle and bone tissues may initially be undetected by clinical observation as it involves fatty infiltration in muscles, formation of atrophic muscle fibers and decrease in muscle mass ${ }^{11-13}$. A post-stroke patient with history of repeated BTX injections may develop gradual muscle atrophy not only of the injected muscles but also of adjacent or distant muscle groups. BTX is frequently used as part of a multi-modal rehabilitation 
plan to manage post-stroke spasticity and to improve overall limb function. Frequent injections to the forearm and smaller muscle groups of the hand predispose the areas to become atrophic, affecting its biomechanical properties and subsequently the bony alignment of the fingers and thumb. Toxin spread can involve areas proximal to the forearm and involve other upper extremity muscle groups. Atrophic muscles not only affect force generation necessary for active voluntary movement, but also for functional use of the whole extremity and other qualities of movement like how smooth an action is performed or the speed of the movement ${ }^{15}$. In the long term, patients may have difficulty in fully participating and continuing their therapy programs as these changes affect motor learning. Al-Oboudi emphasizes that variables that increase the patient's impairments affect his activity or participation level negatively and affect his ability to meet his overall rehab goal of improvement in function at many levels. ${ }^{15}$. These are some scenarios that may occur in actual clinical practice but may not yet be observed in human experimental studies. Little is written about long term repeated BTX injections for post-stroke spasticity coupled by fewer clinicians who report what they find in actual practice in patients receiving longer course therapies, thus this viewpoint needs further consideration by rehab clinicians and those in field of research. Alternatives to longterm and repeated BTX injections for post-stroke spasticity is recommended as it is not known if muscle tissues will go back to pre-injection levels, or return to normal skeletal fibers if general activity level is resumed. ${ }^{11-13}$ It will be a huge error if these $\mathrm{AE}$ are attributed as an extension of the stroke.

Patients receiving BTX and therapy to manage poststroke spasticity may regain some degree of motor control following the weakening of the injected muscle. However, these positive changes may be masked if a patient experience Systemic AE from a repeat series of BTX injections. This scenario need to be taken into consideration when making decisions regarding the course of patient's overall rehabilitation program, and whether to discontinue or continue the course of BTX injections to manage poststroke spasticity. With the increased use of BTX to reduce post-stroke spasticity, clinicians and researchers are asked to take into consideration this clinical commentary for a more informed practice and research.

\section{References}

1. Bakheit Magid A, Bakheit 0. (2006) The possible adverse effects of intramuscular botulinum toxin injections and their management. Curr Drug Saf. 2006; 1:271-279. EndFragment

2. Crowner BE, Torres-Russotto D, Carter AR, Racette BA. Systemic weakness after therapeutic injections of botulinum toxin a: a case series and review of the literature. Clin Neuropharmacol. 2010; 33(5):243-7.

3. Intiso D. Therapeutic use of botulinum toxin in neurorehabilitation. Journal of Toxicology. 2011; doi: 10.1155/2012/802893

4. Varghese-Kroll E, Elovic EP. (2009) Contralateral weakness and fatigue after high-dose botulinum toxin injection for management of poststroke spasticity. Am J Phys Med Rehabil. 2009; 88(6):495-9.

5. Shaw L, Price C, van WIjck F, Shackley P, Steen N, Barnes M, Rodgers H (2011). Botulinum Toxin for the Upper Limb after Stroke (BoTULS) Trial: effect on impairment, activity limitation, and pain. Stroke. 2011; 42 (5):1371-1379.

6. Chang MA. Possible Adverse Effects of Repeated Botulinum Toxin A Injections to Decrease Post- Stroke Spasticity in Adults Undergoing Rehabilitation. Journal of Allied Health. 2015; Vol. 44, No. 3

7. Muller F, Cugy E, Ducerf C, Delleci C, Guehl D, Joseph PA. Safety and self-reported efficacy of botulinum toxin for adult spasticity in current clinical practice: a prospective observational study. Clinical Rehabilitation. 2011; 26 (2), 174-179.

8. Roche N, Schnitzler A, Genêt F F, Durand MC, Bensmail D (). Undesirable Distant Effects Following Botulinum Toxin Type. A Injection. Clinical Neuropharmacology. 2008; 31(5): 272-280.

9. Gordon MF, Brashear A, Elovic E, Kassicieh D, Marciniak C, Liu J, et al. (2004). Repeated dosing of botulinum toxin type A for upper limb spasticity following stroke. Neurology. 63 (10): 1971-1973.

10.Sheean G, Lannin NA, Turner-Stokes L, Rawicki B, Snow BJ. 0 Botulinum toxin assessment, intervention and after-care for upper limb hypertonicity in adults: international consensus statement. European Journal of Neurology. 2010; 17:74-93.

11.Fortuna R, Vaz MA, Youssef AR, Longino D, Herzog W. Changes in contractile properties of muscles receiving repeat injections of botulinum toxin (Botox). Journal of Biomechanics. 2011; 44:39-44.

12.Warner SE, Sanford DA, Becker BA, Bain SD, Srinivasan S, Gross TS. Botox induced muscle paralysis rapidly degrades bone. Bone. 2006; 38(2):257-264.

13.Grimston SK, Silva MJ, Civitelli R. Bone Loss after Temporarily Induced Muscle Paralysis by Botox Is Not Fully Recovered After 12 Weeks. Annals of the New York Academy of Sciences. 2007; 1116: 444-460. doi: 10.1196/annals.1402.009

14. Raphael KG, Tadinada A, Bradshaw JM, Janal MN, Sirois DA, Chan KC. et al. Osteopenic consequences of botulinum toxin injections in the masticatory muscles: a pilot study. Journal of Oral Rehabilitation. 2014.

15.Al-Oboudi W. Neuro-IFRAH Institute Self-Evident Effective Therapy. Post-Stroke Rehabilitation Symposium. http:// www.pacificstrokeassociation.org/index.php/events/ poststrokerehabsymposium 